\title{
Microstructures and Tribological Properties of TiC Reinforced FeCoNiCuAl High-Entropy Alloy at Normal and Elevated Temperature
}

\author{
Tie Zhu ${ }^{1}$, Hong Wu ${ }^{1,2,3, *}$, Rui Zhou ${ }^{1}$, Ningyi Zhang ${ }^{4}$, Yong Yin ${ }^{1}$, Luxin Liang ${ }^{1}$, Yong Liu ${ }^{1}$, \\ Jia Li ${ }^{5}$, Quan Shan ${ }^{6}{ }^{(1)}$, Qingxiang $\mathrm{Li}^{2}$ and Weidong Huang ${ }^{3}$ \\ 1 State Key Laboratory of Powder Metallurgy, Central South University, Changsha 410083, China \\ 2 Shenzhen Zhong Jin Ling Nan Nonfemet Co., Ltd., Shenzhen 518040, China \\ 3 School of Materials Science and Engineering, Northwestern Polytechnical University, Xi'an 710072, China \\ 4 College of Mechanical and Vehicle Engineering, Hunan University, Changsha 410082, China \\ 5 State Key Laboratory of Advanced Design and Manufacturing for Vehicle Body, Hunan University, \\ Changsha 410082, China \\ 6 School of Materials Science and Engineering, Kunming University of Science and Technology, \\ Kunming 650093, China \\ * Correspondence: hwucsu@csu.edu.cn; Tel.: +86-731-8887-7669
}

Received: 16 January 2020; Accepted: 4 March 2020; Published: 18 March 2020

check for updates

\begin{abstract}
Recent studies have suggested that high-entropy alloys (HEAs) possess high fracture toughness, good wear resistance, and excellent high-temperature mechanical properties. In order to further improve their properties, a batch of TiC-reinforced FeCoNiCuAl HEA composites were fabricated by mechanical alloying and spark plasma sintering. X-ray diffractometry analysis of the TiC-reinforced HEA composites, combined with scanning electron microscopy imaging, indicated that $\mathrm{TiC}$ particles were uniformly distributed in the face-centered cubic and body-centered cubic phases. The room temperature hardness of the FeCoNiCuAl HEA was increased from 467 to $768 \mathrm{HV}$ with the addition of $\mathrm{TiC}$, owing to precipitation strengthening and fine grain strengthening effects. As the TiC content increased, the friction coefficient of the FeCoNiCuAl HEA first increased and then decreased at room temperature, due to the transition of the wear mechanism from adhesive to abrasive behavior. At higher temperature, the friction coefficient of the FeCoNiCuAl HEA monotonously reduced, corresponding well with the transition from adhesive wear to oxidative wear.
\end{abstract}

Keywords: high-entropy alloy; TiC; tribological properties; wear mechanism

\section{Introduction}

In recent years, a novel class of solid-solution metallic alloys, named high-entropy alloys (HEAs) or multi-primary element alloys (MPEAs), has attracted widespread attention [1]. They usually contain five components ranging from $5 \%$ to $35 \%$ (atomic percentage, at $\%$ ). Compared to traditional alloys, the HEAs exhibit various excellent properties in their strength, wear resistance, thermally-stable microstructure, oxidation, and corrosion resistance [2-4], indicating large potential applications at high temperature in engineering fields.

The microstructures and properties of the FeCoNiCuAl HEA have been widely studied over the past decade [5-7]. The addition of the aluminum ( $\mathrm{Al}$ ) element can not only increase lattice distortion and elastic energy, but also promote the formation of the body-centered cubic (BCC) phase. Therefore, it is helpful to increase the strength and hardness of HEAs. Simultaneously, the density of HEAs is significantly reduced by adding lightweight aluminum. Moreover, the addition of the copper $(\mathrm{Cu})$ element can stabilize the face-centered cubic (FCC) phase and improve the hardness, ductility, and 
wear resistance of HEAs [8,9]. Recently, it was reported that the addition of Cu can reduce the wear rate of $\mathrm{CoCrFeNiCux} \mathrm{HEAs} \mathrm{at} \mathrm{both} \mathrm{room} \mathrm{temperature} \mathrm{and} \mathrm{elevated} \mathrm{temperatures,} \mathrm{and} \mathrm{wear} \mathrm{resistance}$ at elevated temperatures is promoted more significantly than that at room temperature due to their self-lubricating mechanism [10].

However, the major challenge for practical applications of the FeCoNiCuAl HEA is its insufficient strength. Recent studies have indicated that the precipitation of reinforcing phases in various materials, such as HEAs and ceramics, can further increase the yield strength of the alloy while maintaining relatively high ductility [11-13]. For instance, the precipitation of SiC nanoparticles in FeCoCrNiMn enhanced the compressive yield strength from 1180 to $1480 \mathrm{MPa}$ at room temperature [14]. The precipitation of WC in the FeCoCrNi HEA leads to an improved hardness up to 768HV, which corresponds well with the transition of the wear mechanism [13]. The alloy may also be strengthened by dispersion strengthening, which can significantly improve the strength and hardness of the alloy, and reduce the plasticity and toughness slightly [15]. TiC is considered a good candidate as the strengthening phase due to its high melting point, high hardness, low density, good metal matrix wettability, good chemical stability, and excellent wear resistance [16]. The optimized yield strength of the $(\mathrm{FeCrNiCo}) \mathrm{Al}_{0.75} \mathrm{Cu}_{0.25}$ HEA reinforced by $\mathrm{TiC}$ particles can reach $1637 \mathrm{MPa}$, which is increased by $90.6 \%$ compared to the (FeCrNiCo) $\mathrm{Al}_{0.75} \mathrm{Cu}_{0.25} \mathrm{HEA}$ [17]. However, the precipitation of ceramic nanoparticles in the metal matrix tends to be unevenly distributed, which is probably originated from the instability of the interfaces between the ceramic particles and the metal matrix [18-20]. In order to make the second phase uniformly distributed in the matrix, in situ methods are widely used to fabricate composites with a nanosized ceramic strengthening phase [21,22]. In general, a composite material is fabricated by an in-situ reaction of additives and carbon-based abrasives via the method of powder metallurgy [23]. Particularly, spark plasma sintering (SPS), a powder metallurgy process, provides fast processing of the feedstock, the suppression of grain coarsening and the production of specimens with a low porosity $[24,25]$. The combination of the ultra-fine grain and nanosized reinforcing particles can enhance the strength of the composite material through the Hall-Petch effect and the strengthening of dislocations $[26,27]$. At the same time, the in-situ method can make the interfaces between the ceramic and the metal substrate cleaner, showing stronger bonding forces between materials that strengthen the mechanical properties of the composite material [28].

As demonstrated above, the precipitation strengthening effects in HEAs have been extensively investigated [13,14,29-33]. However, the high-temperature tribological properties of ceramic-reinforced HEAs have rarely been reported. In the present study, FeCoNiCuAl HEA composites reinforced by in situ-generated TiC ceramic particles were fabricated by mechanical alloying (MA) followed by SPS. The microstructures, phase compositions, and hardness of the FeCoNiCuAl-TiC composites were characterized, respectively. The effect of strengthening phases on the high-temperature tribological properties of the HEA was studied, and the related mechanism was discussed.

\section{Experimental}

The pre-alloyed powder of the FeCoNiCuAl HEA was prepared using gas atomization in a high-purity argon atmosphere to avoid oxidation. The particle size of the HEA powder was measured by a laser particle size analyzer (MASTERSIZER3000, Malvern, Worcestershire, UK). The average particle size of the HEA powder was approximately $9.2 \mu \mathrm{m}$. The equiatomic-ratio FeCoNiCuAl HEA was mixed with varying compositions ( $0 \mathrm{wt} \%, 10 \mathrm{wt} \%, 20 \mathrm{wt} \%$, $30 \mathrm{wt} \%)$ of $\mathrm{Ti}$ powder and graphite nanoparticles (around $100 \mathrm{~nm}$ ) in a high-energy planetary ball milling machine (MITR YXQM-4L, MITR, Changsha, China) for $5 \mathrm{~h}$. The milling speed was $250 \mathrm{rpm}$, and the ball-to-powder weight ratio was 10:1. Ethanol was used as a processing control agent to avoid cold welding. The as-milled powders were then consolidated by spark plasma sintering (SPS; FCT D25/3) in a 40 mm graphite die at a sintering temperature of $1000{ }^{\circ} \mathrm{C}$ under $30 \mathrm{MPa}$ pressure for $10 \mathrm{~min}$. Graphite foils with applied $\mathrm{BN}$ coating were placed between the powders and the die walls to avoid possible contamination. 
The as-SPSed bulk specimens were polished using standard metallographic silicon carbide papers supplemented with colloidal silica powders (Struers OPS).

The phase composition of the HEA-TiC composite was analyzed using a D/max 2500pc X-ray diffractometer (XRD) (Advance D8, Bruker, Karlsruhe, Germany) with $\mathrm{Cu}-\mathrm{Ka}$ radiation $(\mathrm{k}=0.154 \mathrm{~nm})$. The microstructure observation was conducted by a scanning electron microscope (SEM) equipped with energy dispersive spectrometer (EDS) and electron backscatter diffraction (EBSD) (FEI Nova Nano230). The hardness of the specimens was measured by a micro-Vickers hardness tester at a load of $5 \mathrm{~kg}$ for $15 \mathrm{~s}$ (HVS-5). The micro-hardness of each phase was determined by an Ultra Nanoindenter (UNHTL $+\mathrm{MCT}$, CSM, Switzerland) under the load of $30 \mathrm{mN}$ for $10 \mathrm{~s}$. The wear tests were performed using a HT-1000 ball-on-disk tribometer (HT-1000, Lanzhou ZhongKeKaiHua Technology Development Co. Ltd, Lanzhou, China) under constant applied normal load of $10 \mathrm{~N}$ at a line speed of $0.5 \mathrm{~m} / \mathrm{s}$ for $30 \mathrm{~min}$ and at the testing temperatures of 20 and $600{ }^{\circ} \mathrm{C}$, respectively. Commercial $\mathrm{Si}_{3} \mathrm{~N}_{4}$ balls were used as the counterface. The diameter of the $\mathrm{Si}_{3} \mathrm{~N}_{4}$ balls was $6 \mathrm{~mm}$. The volumetric loss of the alloy was measured using a contact surface profilometer (Keyence VHX-5000). The volume wear rate was calculated by the formula $W=V / S L$, where $\mathrm{W}$ is the volume wear rate, $\mathrm{V}$ is the volumetric wear loss, $\mathrm{S}$ is the sliding distance, and $\mathrm{L}$ is the normal load. To ensure reproducibility, the wear tests were performed at least three times at both room and high temperature. The mean value of the wear rates was calculated. The worn surfaces of the specimens were examined by SEM.

\section{Results}

\subsection{Microstructures}

Figure 1a shows XRD patterns of the HEA composite powders after ball milling. The HEA powders consisted mainly of FCC and BCC phases. As for the as-milled HEA-TiC powders, diffraction peaks of Ti and graphite were distinctly observed. The peak intensity of Ti and graphite increased with the increase in Ti and graphite contents. The XRD patterns of SPSed specimens are shown in Figure $1 \mathrm{~b}$. Likewise, the SPSed HEA still comprised FCC and BCC phases. In the HEA-TiC composites, the peaks of $\mathrm{Ti}$ and graphite disappeared instead of $\mathrm{TiC}$ peaks, which indicate the formation of $\mathrm{TiC}$ during the sintering process. Table 1 presents the mixed enthalpy between carbon and several metal elements. Considering the lowest value of mixed enthalpy between $\mathrm{Ti}$ and $\mathrm{C}$, the formation of $\mathrm{TiC}$ is reasonable and consistent with that reported by Yim [17]. According to the XRD data, the equilibrium lattic e constants of the FCC and BCC phases in the HEA were calculated as 3.521 and $2.881 \AA$, respectively, while the lattice constants of FCC and BCC phases in the composites were 3.53 and $2.884 \AA$, respectively. This discrepancy is probably due to the solid solution effect of the $C$ atoms in the matrix [21,22].
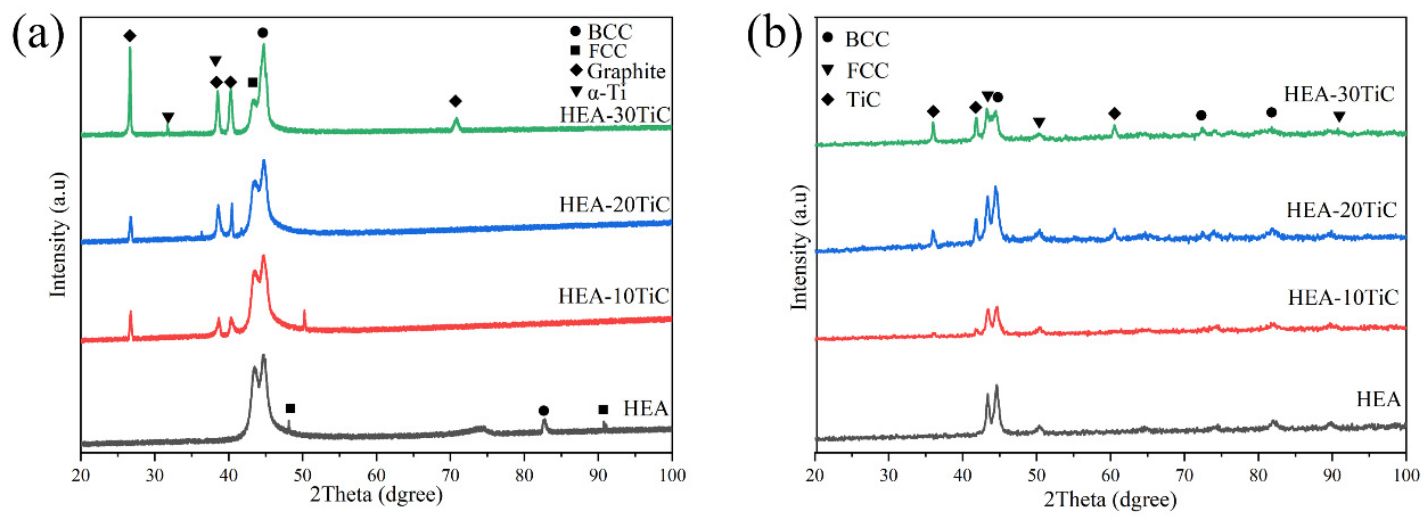

Figure 1. XRD patterns of (a) HEA-TiC composite as-milled powders and (b) as-SPSed HEA-TiC composites. 
Table 1. The mixing enthalpy of different atomic pairs [34].

\begin{tabular}{ccccccc}
\hline$\Delta \boldsymbol{H}_{\text {mix }}, \mathbf{k J} / \mathbf{m o l}$ & $\mathbf{F e}$ & $\mathbf{C o}$ & $\mathbf{N i}$ & $\mathbf{C u}$ & $\mathrm{Al}$ & $\mathrm{Ti}$ \\
\hline $\mathrm{C}$ & -50 & -42 & -39 & -33 & -36 & -109 \\
\hline
\end{tabular}

During the MA process, oxidation inevitably occurs and oxides are commonly included in the alloys [35]. Figure 2 presents the microstructures of the sintered HEAs. In addition to the alloy matrix, there are two types of impurities, i.e., white particles attached on the surface (Figure 2a) and black spots dispersed in the matrix (Figure $2 b$ ). The white particles are presumed to be silica powders in oxide polishing solution (OPS) owing to their similar size $(0.04 \mu \mathrm{m})$, while the black spots correspond to oxides $[17,36]$. The impurities are generally introduced by the milling medium and/or the process controlling agent (PCA) during the MA process [37,38].
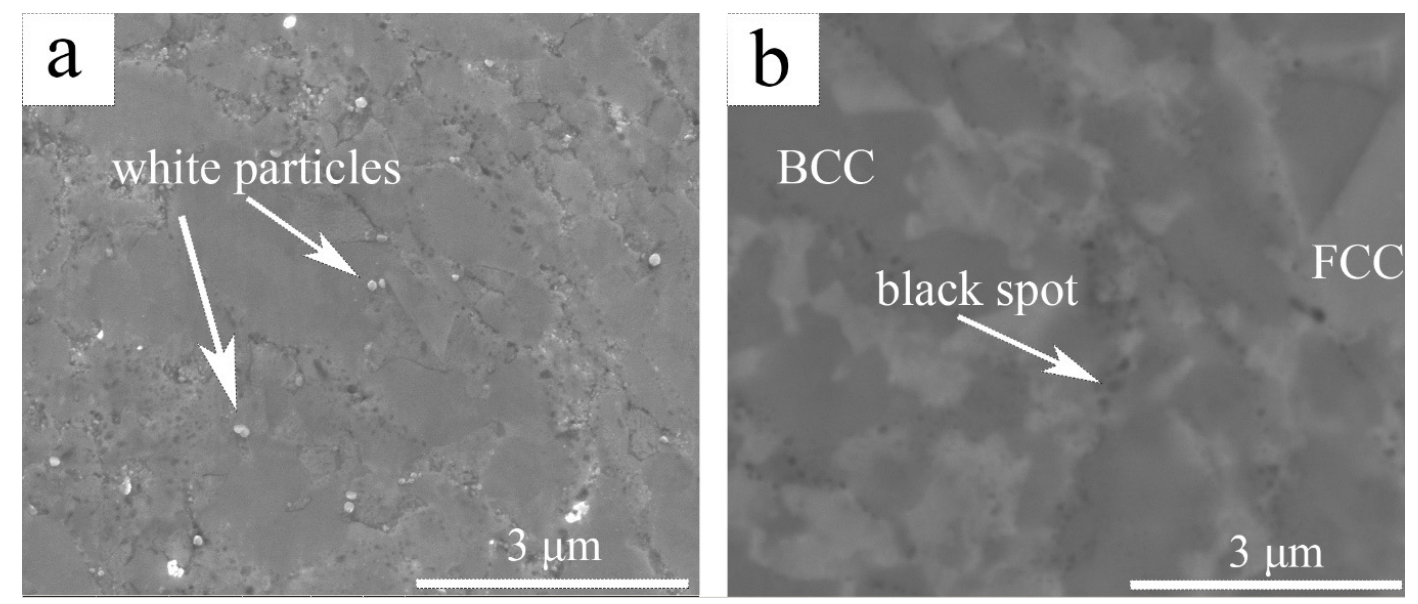

Figure 2. (a) Scanning electron (SE) and (b) backscattered electron (BSE) images of the microstructures of the SPSed HEA.

As shown in Figure $2 b$, the HEA consists mainly of a gray phase and a white phase, corresponding to the FCC and BCC phases, respectively, which is in accord with the results reported by Beyramali Kivy et al. [8]. It was reported that $\mathrm{Ni}$ and $\mathrm{Al}$ show high concentrations in the $\mathrm{BCC}$ phase, while $\mathrm{Cu}$ was abundant in the FCC phase [39]. The EDS analysis results of the bright and dark areas in Figure 2b are listed in Table 2. According to this result, the crystal structure of the bright area was FCC phase and the gray area was BCC phase. The microstructures of HEA-TiC composites with different TiC contents are presented in Figure 3. A number of black dots with a diameter of $0.3 \mu \mathrm{m}$ were uniformly distributed in the FCC and BCC phases. The composition of the black phase is exhibited in Figure 4, indicating the formation of TiC particles in the HEA. The distribution of TiC particles in the HEA was uneven; it is easier to precipitate in the FCC phase due to the FCC structure of TiC [29]. In the HEA-TiC composites, with increasing $\mathrm{Ti}$ and graphite contents, the content of $\mathrm{TiC}$ increased.

Table 2. Chemical compositions of the FCC phase, BCC phase, and TiC phase.

\begin{tabular}{cccccccc}
\hline $\begin{array}{c}\text { Chemical } \\
\text { Composition }\end{array}$ & Fe & Co & Ni & Cu & Al & Ti & C \\
\hline FCC & 26.7 & 21.4 & 17.0 & 27.0 & 7.3 & - & - \\
BCC & 23.2 & 24.0 & 25.0 & 7.8 & 19.7 & - & - \\
TiC & 5.1 & 5.3 & 5.3 & 2.2 & 3.3 & 53.3 & 25.6 \\
\hline
\end{tabular}



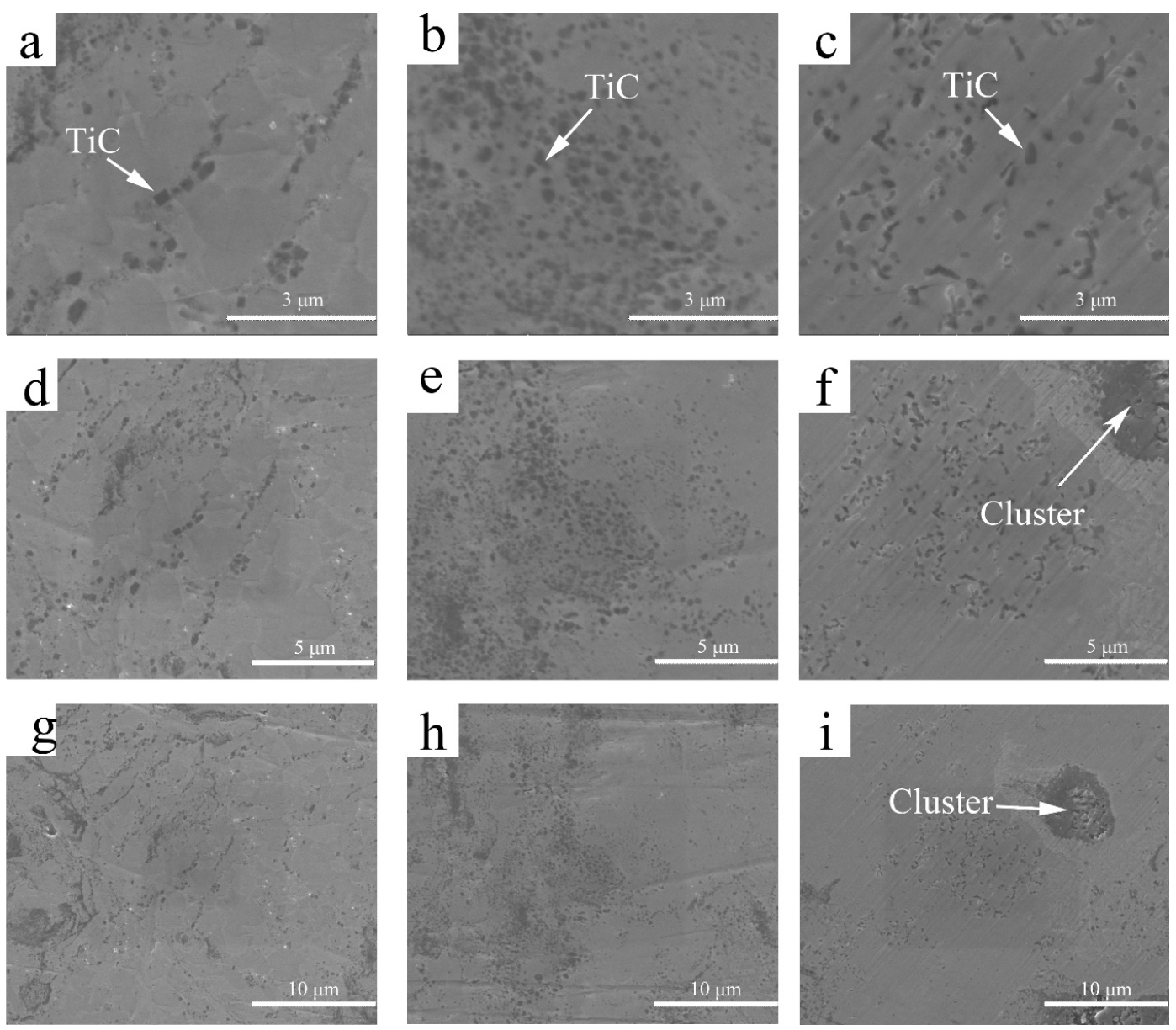

Figure 3. SE images of the microstructures of the SPSed $(\mathbf{a}, \mathbf{d}, \mathbf{g})$ HEA-10TiC, $(\mathbf{b}, \mathbf{e}, \mathbf{h})$ HEA-20TiC, and $(\mathbf{c}, \mathbf{f}, \mathbf{i})$ HEA-30TiC composites.
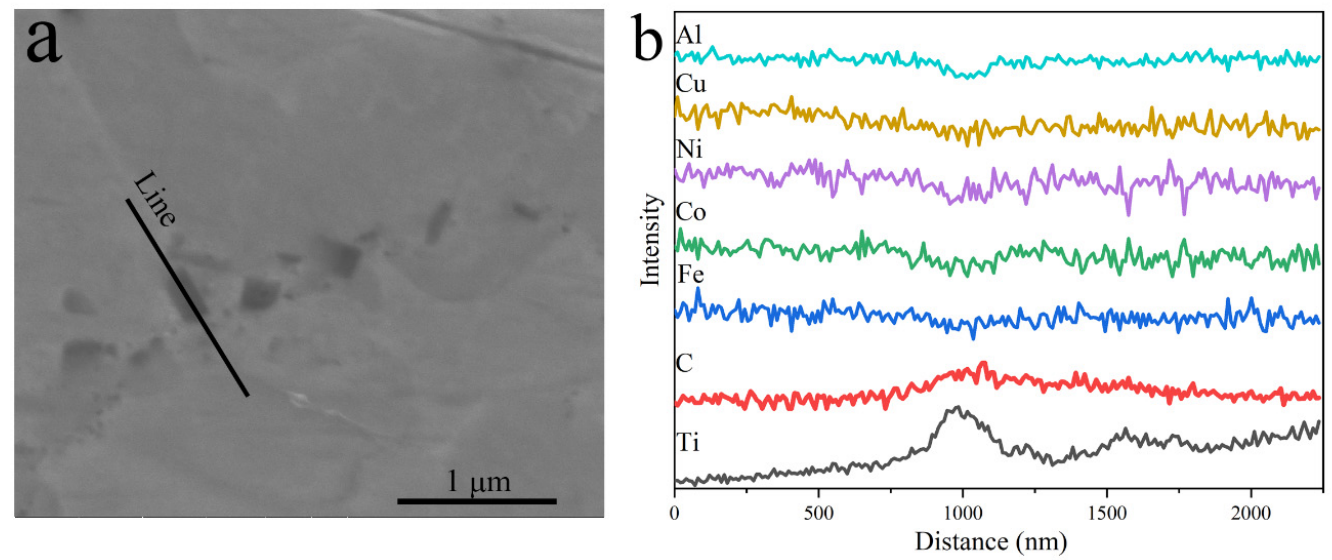

Figure 4. (a) SEM image showing the position of the line scan and (b) compositional profiles of the Tiand C-rich carbide in the HEA-10TiC composite.

Figure 5 exhibits the EBSD inverse pole figure (IPF) maps of the HEA and the $10 \mathrm{wt} \%$ HEA-TiC composite. TiC particles were observed in the XRD patterns (Figure 1) and SEM images (Figure 3). However, they were not detected in EBSD maps due to the limited particle size of TiC. It is apparent that the average grain size of the $10 \mathrm{wt} \%$ HEA-TiC composite is smaller than that of the HEA. The addition of $\mathrm{TiC}$ can suppress the growth of grains during sintering, leading to the refinement of the grains in the HEA matrix. Figure $5 c$,d present the phase compositions of the HEA and the HEA-10TiC composite, 
respectively. The FeCoNiCuAl HEA is mainly composed of the BCC phase and a small amount of the FCC phase. With the addition of Ti and graphite, the content of FCC increases from 11.9\% in the HEA to $19.2 \%$ in the HEA-10TiC composite.
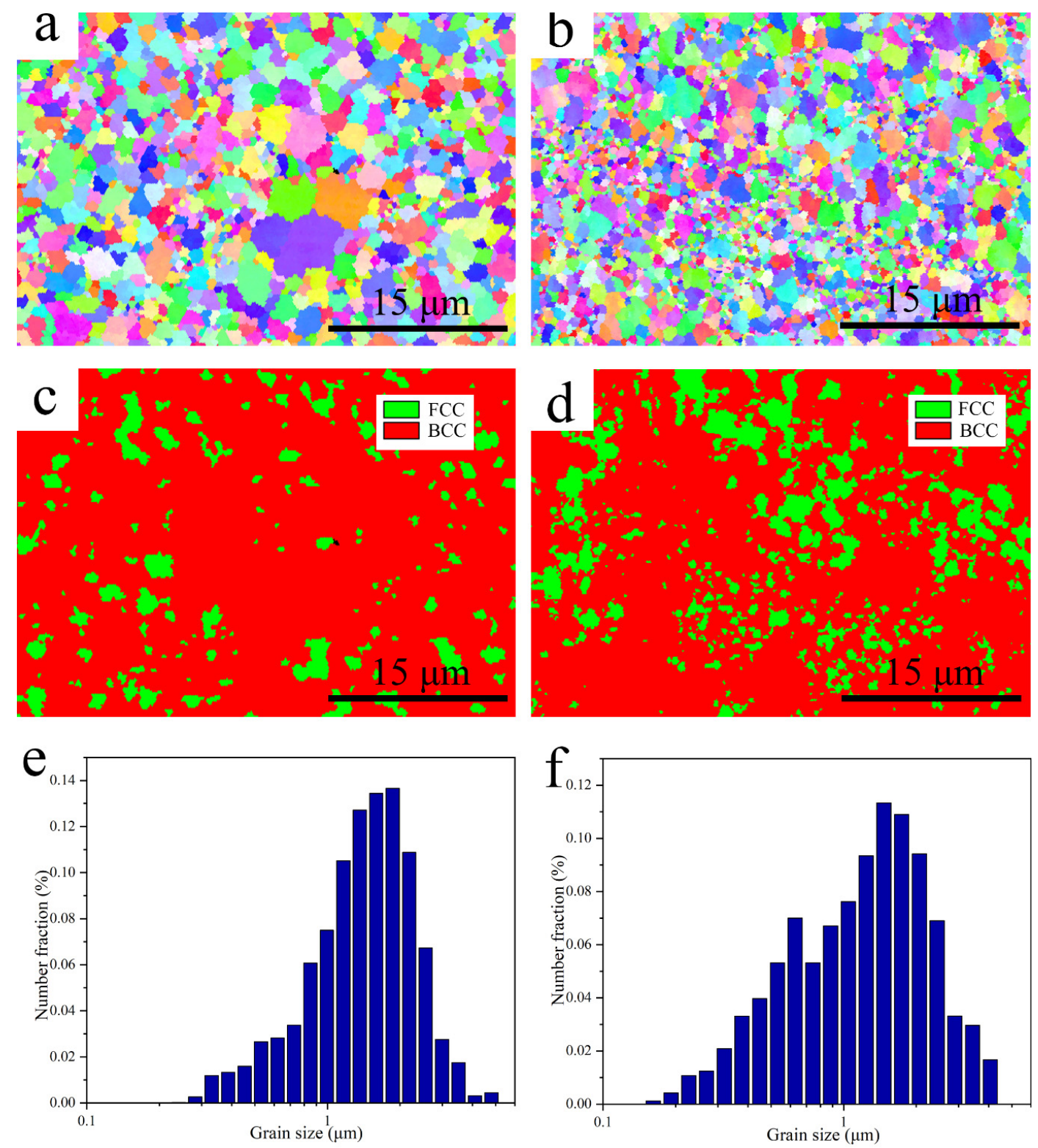

Figure 5. Inverse pole figure (IPF) maps of the SPSed (a) HEA and (b) HEA-10TiC, phase composition of the SPSed (c) HEA and (d) HEA-10TiC, and grain size of the SPSed (e) HEA and (f) HEA-10TiC.

\subsection{Hardness}

The hardness of the HEA-TiC composites is shown in Figure 6a. As the content of TiC increases, the hardness of the composites remarkably increases from 467 to $768 \mathrm{HV}$. The micro-hardness of the matrix phase, $\mathrm{TiC}$ particles, and the interface between $\mathrm{TiC}$ particles is illustrated in Figure $6 \mathrm{~b}$. The result indicated that the agglomerated TiC exhibited the highest micro-hardness (1489 HV) among all phases. The micro-hardness of the interface was about $916 \mathrm{HV}$, and the matrix phase showed the lowest micro-hardness of only $570 \mathrm{HV}$. The high hardness of the TiC particles may contribute to the improvement of the wear resistance of the HEA-TiC composites. Figure 6c presents typical loading-unloading curves for indentations with a $50 \mathrm{mN}$ load. The TiC particle showed a higher elastic modulus than that of the matrix phase. 
(a)
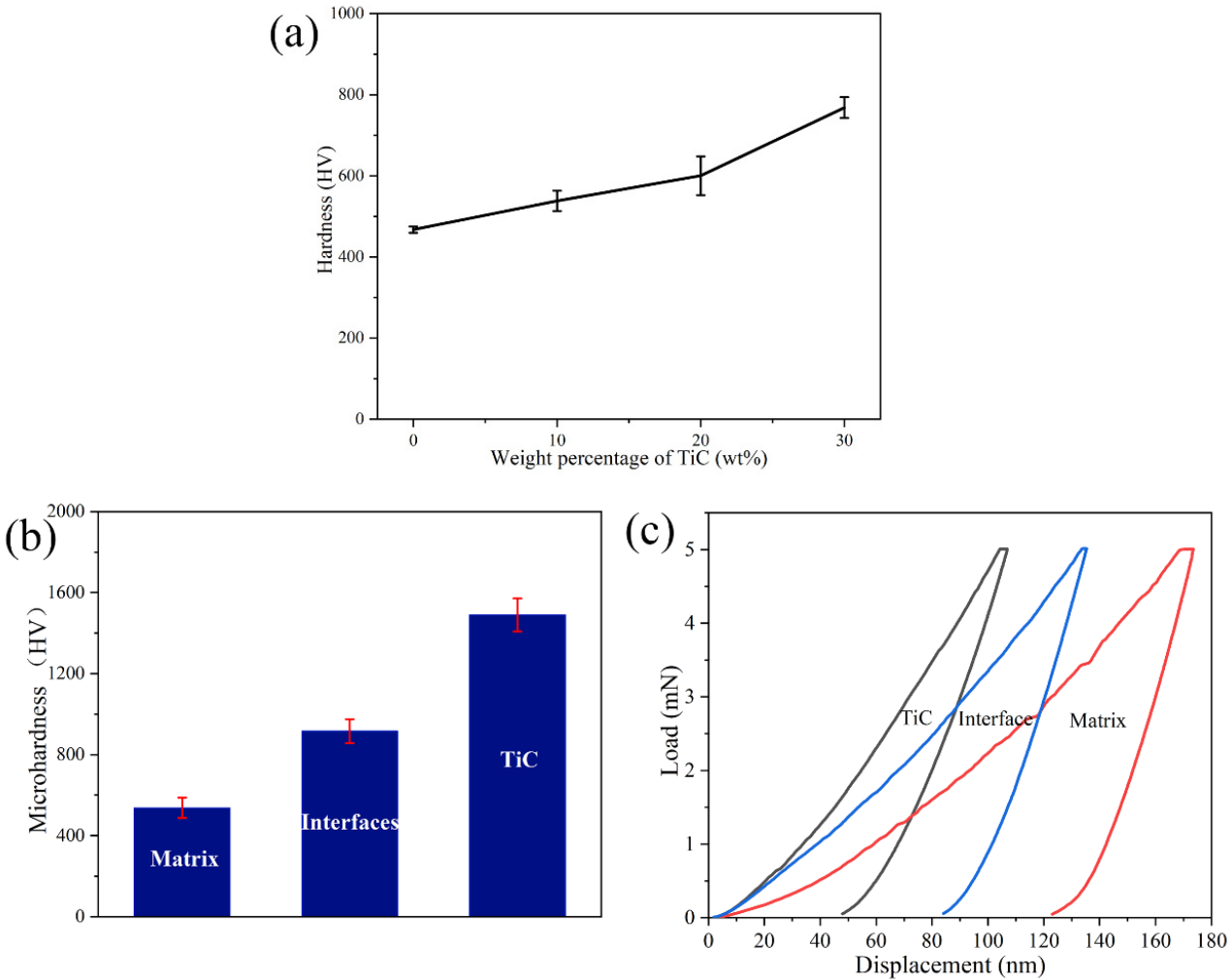

Figure 6. (a) Hardness of HEA-TiC composites; (b) micro-hardness of different regions in the HEA-10TiC composites; (c) load-displacement curves of different regions in the HEA-10TiC composites.

\subsection{Friction and Wear Properties, Worn Surface, and Debris}

The friction and wear properties of the HEA-TiC composites are shown in Figure 7. The friction coefficients of all specimens sharply increased at the beginning of the wear tests and reached a steady state corresponding to the breaking-in stage. Subsequently, all of the friction coefficient curves remained relatively stable and exhibited periodic waves, which may be owing to periodic accumulation, elimination of debris and the periodic localized fracture of the surface layer [40]. The increase in the friction coefficient was caused by the accumulation of abrasive debris on the wear surface, and the separation of the wear debris from the surface or the filling of the wear cracks caused the reduction of the friction coefficient. As shown in Figure $7 \mathrm{~b}$, the average friction coefficient increased at first and then decreased with further addition of Ti and graphite to $30 \mathrm{wt} \%$. The volumetric wear rate curves of the composites at room temperature are shown in Figure 7c. With the increase in the Ti and graphite contents, the hardness of the composite increased and the wear rate decreased.

Figure 8 shows the worn surface morphologies as well as the debris of HEA-TiC composites. The typical morphologies of both adhesive wear and abrasive wear were observed in the HEAs. When the stress arising from the grinding ball on the worn surface was higher than the yield strength of the HEAs, the deformation process was triggered. Under alternating stress, debris was torn off from the surface and deformed as flakes, as shown in Figure 8e. The EDS results of the worn surface are summarized in Table 3. The oxygen contents of the worn surface increased slightly with the addition of $\mathrm{Ti}$ and graphite, indicating that no considerable oxidation occurred. Figure $8 \mathrm{c}$, d show comparatively rough surface generated by the micro-cutting and micro-plowing of abrasive particles. The furrow-like wear scar along the sliding direction in HEA-TiC composites implied an abrasive wear dominated process. The grinding chips were either particle-like or flake-shaped. With the increase of TiC content, the amount of flaky wear debris decreased, while the particle-like debris increased (Figure 8e-h). 
(a)

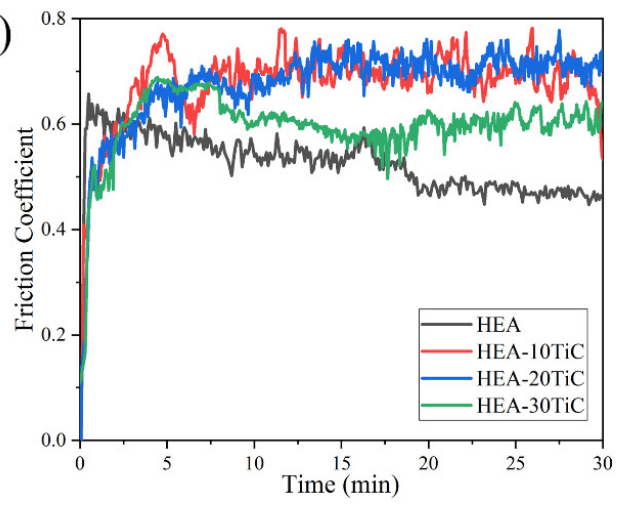

(b)

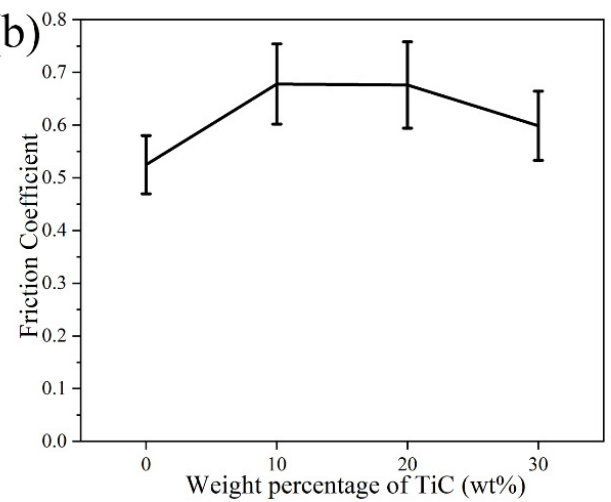

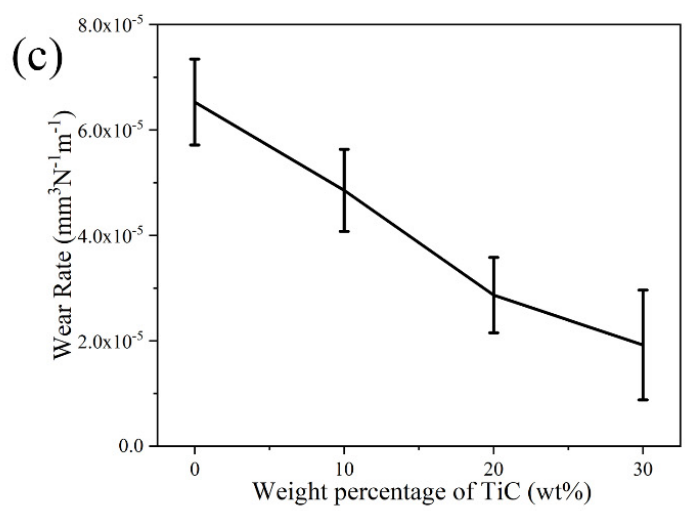

Figure 7. (a) Friction coefficient vs. sliding time. (b) Friction coefficient vs. TiC content. (c) Wear rate of HEA-TiC composites at room temperature.
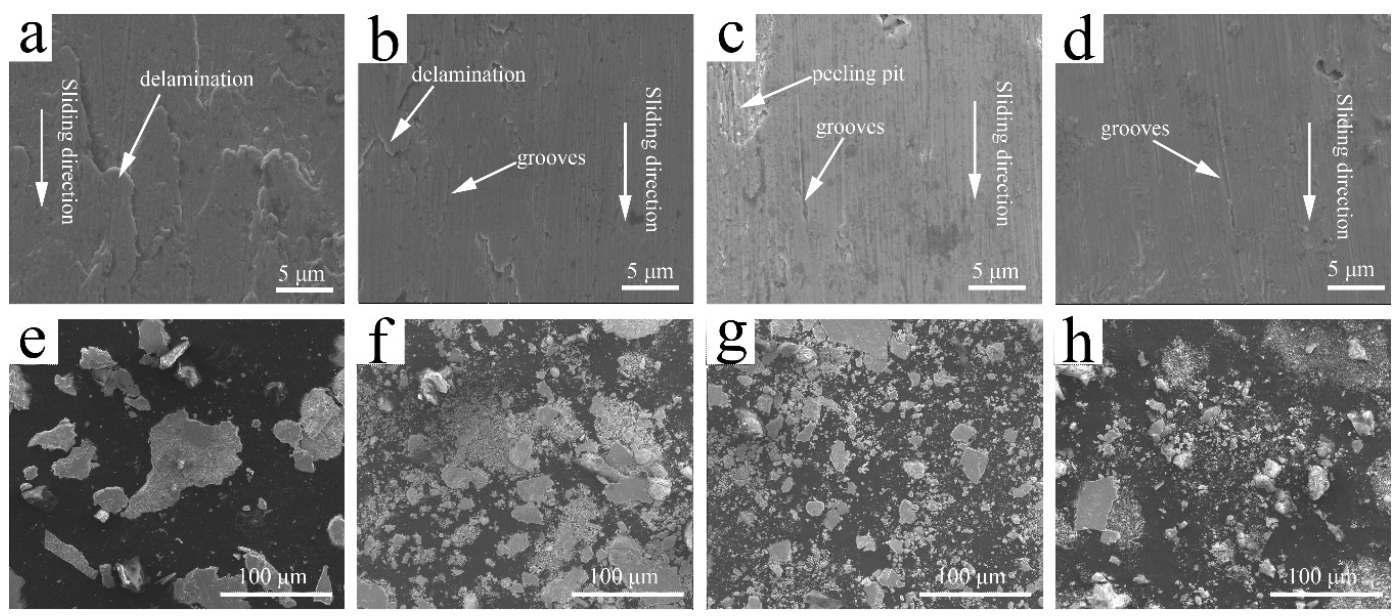

Figure 8. SEM images of the worn surface of (a) HEA, (b) HEA-10TiC, (c) HEA-20TiC, and (d) HEA-30TiC composites and corresponding debris of (e) HEA, (f) HEA-10TiC, (g) HEA-20TiC, and (h) HEA-30TiC composites after wear at room temperature.

Table 3. Chemical compositions of the surface wear-tested at room temperature, in atomic percentage.

\begin{tabular}{ccccccccc}
\hline $\begin{array}{c}\text { Chemical } \\
\text { Composition }\end{array}$ & Fe & Co & Ni & Cu & Al & Ti & C & O \\
\hline TiC00 & 21.3 & 22.0 & 21.2 & 11.0 & 19.6 & - & - & 4.9 \\
TiC10 & 16.1 & 13.5 & 12.3 & 17.9 & 12.5 & 8.5 & 12.7 & 6.6 \\
TiC20 & 15.5 & 15.3 & 14.8 & 8.8 & 13.7 & 14.4 & 10.7 & 7.0 \\
TiC30 & 10.7 & 10.3 & 9.8 & 9.2 & 8.6 & 24.0 & 15.9 & 11.4 \\
\hline
\end{tabular}


The friction and wear properties of the HEA-TiC composites at high temperature are shown in Figure 9. As shown in Figure 9a, the friction coefficient of the HEA was unstable and exhibited drastic fluctuation, which may be related to the aggregation of large debris. In contrast, the friction coefficients of the HEA-TiC composites remained comparatively stable after the run-in period. With the addition of $\mathrm{Ti}$ and graphite, the average friction coefficient dropped considerably (Figure 9b). As plotted in Figure 9c, the wear rate of the HEA was significantly higher than that of the HEAs-TiC composites. However, it clearly presented only small wear scatters among the HEA-TiC composites, which is mainly ascribed to the transition of the wear mechanism. This will be further clarified in the Discussion section. Recent work by Moravcikova-Gouvea et al. [41] reported that a HEA produced by MA and SPS exhibited better wear resistance than traditional AISI 52,100 and Inconel 713 alloys, and suggested that powder metallurgy provides a good approach to fabricating HEAs with fine-grained microstructures and enhanced wear resistance. Similarly, in the present study, the wear rates of the HEA-TiC composites have the same order of magnitude $\left(10^{-5} \mathrm{~mm}^{3} / \mathrm{Nm}\right)$ at room temperature, while the high-temperature wear rates of the TiC-containing specimens are dramatically lower than that of the TiC-free specimen, and even other HEAs, by at least one order of magnitude [42,43].
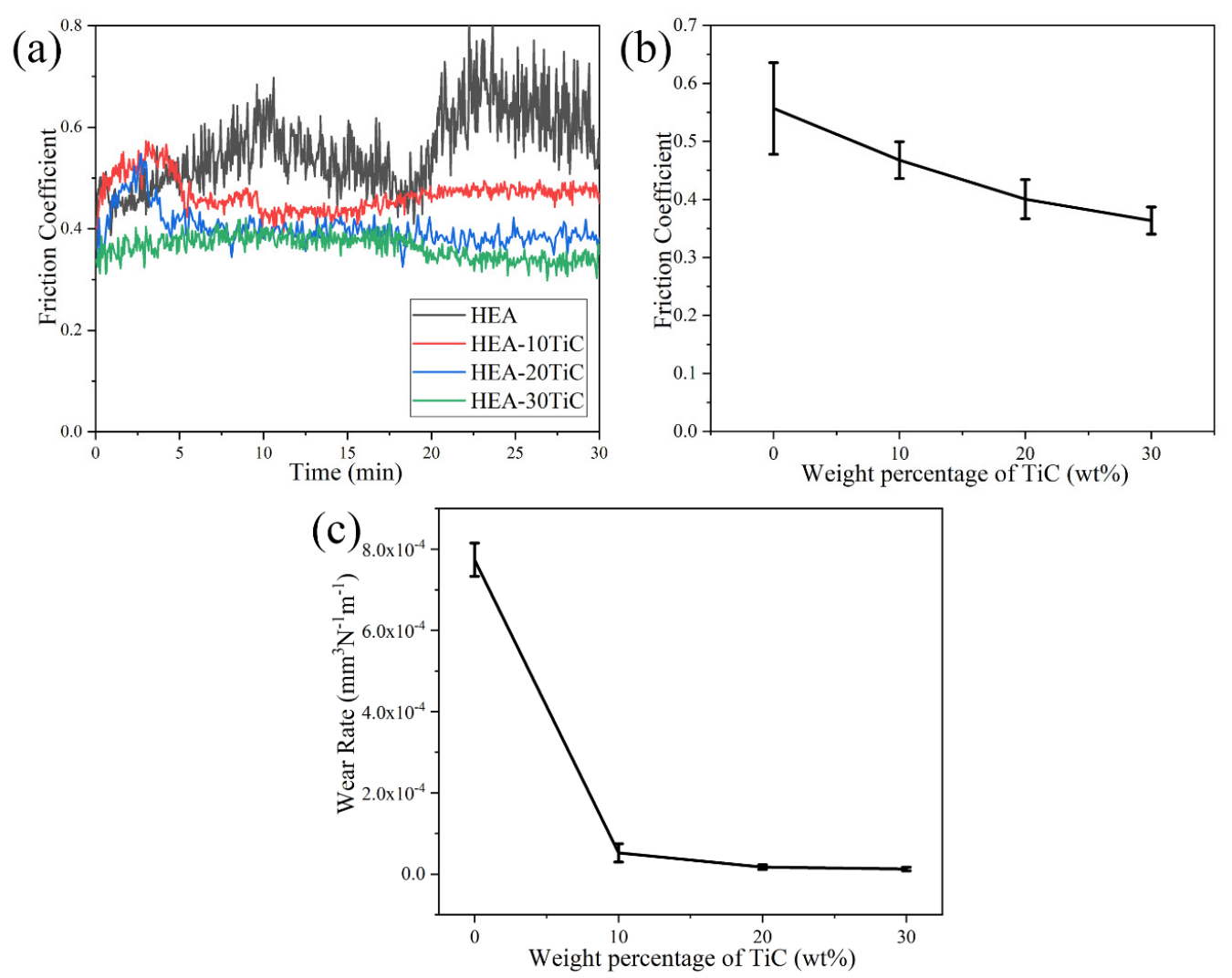

Figure 9. (a) Friction coefficient vs. sliding time. (b) Friction coefficient vs. TiC content (c). Wear rate of HEA-TiC composites at high temperature.

Figure 10 exhibits the worn surface and debris of the HEA-TiC composites at high temperature $\left(600{ }^{\circ} \mathrm{C}\right)$. The worn surface of the HEA was smooth (Figure 10a), and large pieces of flake-like debris were peeled off from the wear surface (Figure 10e). These indicated the occurrence of severe adhesive wear. In contrast, the high-temperature worn surfaces of the HEA-TiC composites were relatively smoother, and smearing of the wear scars occurred (Figure 10b-d). The material of interface contact points was soft, and a metal-like film on the friction surface was formed. The metal-like film can act as a lubricating agent, and result in a considerably reduced friction coefficient. The grinding chips generated by wear tests performed at high temperature were primarily particle-like (Figure 10f-h). With the increase of TiC content, the amount of wear debris decreased and the size reduced. 

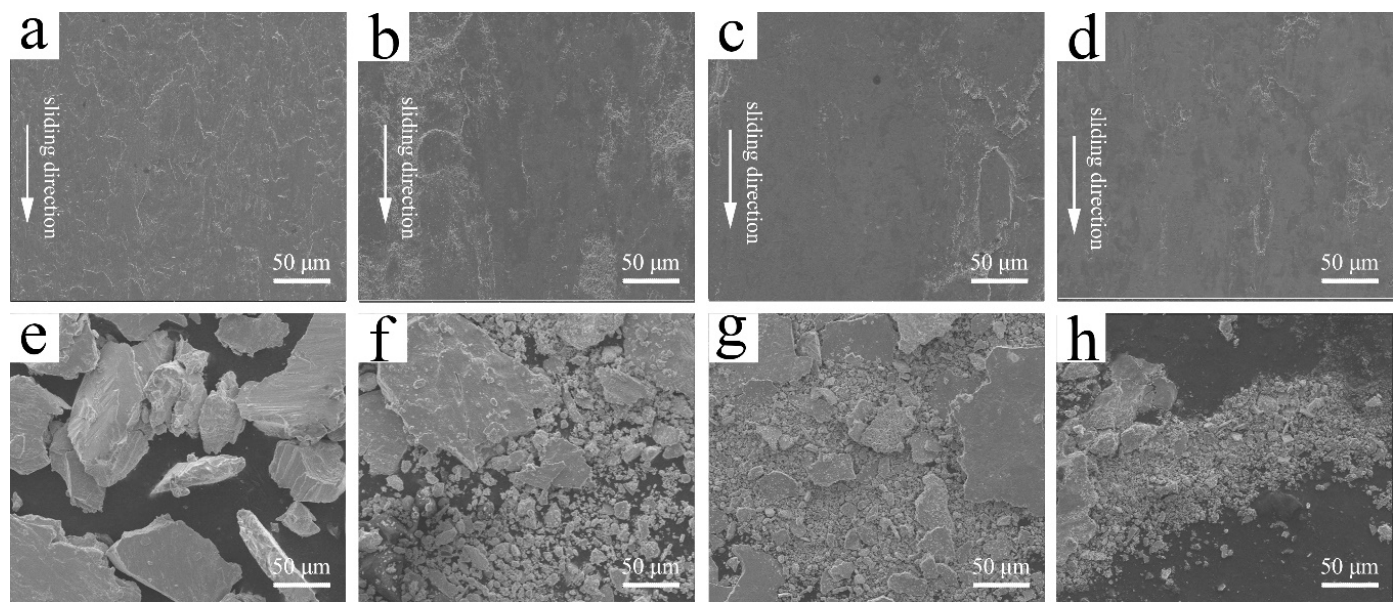

Figure 10. SEM images of the worn surface of (a) HEA, (b) HEA-10TiC, (c) HEA-20TiC, and (d) HEA-30TiC composites and corresponding debris of (e) HEA, (f) HEA-10TiC, (g) HEA-20TiC, and (h) HEA-30TiC composites after wear at high temperature.

\section{Discussion}

\subsection{Microstructures}

It is well accepted that the microstructure plays a significant role in the wear resistance of materials. In the present study, the microstructure of the FeCoNiCuAl HEA was mainly composed of the FCC and BCC phases. The EDS results indicated that Co was almost uniformly distributed in both phases compared to other elements. $\mathrm{Ni}$ and $\mathrm{Al}$ showed relatively higher concentrations in the $\mathrm{BCC}$ phase, while $\mathrm{Cu}$ and Fe were abundant in the FCC phase. These are consistent with other reports $[8,9,44]$. The precipitation mechanism for the ordered $\mathrm{Al}-\mathrm{Ni}$-rich matrix phase is spinodal decomposition due to the large mixing enthalpy between $\mathrm{Al}$ and $\mathrm{Ni}[29,45]$. With the addition of $\mathrm{Ti}$ and graphite, the grain size reduced. As shown in Figure 3, the segregation of the TiC ceramic particles in the HEA matrix may be attributed to the dual-phase structure [29]. The volume fraction of $\mathrm{TiC}$ increased accompanied by the increasing incorporation of Ti and graphite. Large clusters were observed in the HEA-30TiC composites (Figure 3F,I).

\subsection{Wear Behavior}

During the sliding processes, the HEA-TiC composites exhibited excellent wear resistance. The reason for this may be explained as follows. First, TiC, acting as a strengthening phase, can effectively reduce the plastic deformation of the matrix during sliding, thus improving the wear resistance of the composites [46]. Second, the grain sizes of the HEA-TiC composites were lower than that of the HEA. The TiC particles can inhibit the growth of grains to obtain finer grains, thereby enhancing the strength and hardness. According to Archard's law, assuming that it is under the condition of adhesive wear and sliding spherical asperities deform fully plastically in contact, the wear resistance of the material is proportional to its hardness, and thus it will be promoted as well $[47,48]$. Thus, the wear resistance of the HEA-TiC composites was better than that of the HEA due to their high hardness [40]. Further, the excellent antioxidation properties in the composites are proposed to improve the wear resistance [49]. The EDS results of the HEA-TiC composites indicated that the existence of oxidized layers can effectively prevent direct metal-metal contact and impede adhesive wear. Therefore, the wear rate of the HEA-TiC composites was further reduced with the increase in Ti and graphite.

The EDS results exhibit that the contents of $\mathrm{Cu}$ and $\mathrm{O}$ are remarkably high (Table 4), which indicates the presence of an oxide layer, thus improving the wear properties $[10,40]$. During wear tests conducted at high temperature, the formation of an oxidation layer, acting as a lubricating film, is 
easier than the tests performed at room temperature. This implied that oxidative wear was dominated. Two competitive processes may coexist. The debris peels off from the composites, and oxidation layers are formed by cold welding. Meanwhile, the fragmentation of the oxidation layer continually occurs to produce new debris [50]. In the HEA, the debris are not well compacted, which makes them easy to remove and gives rise to the enhancement of wear rate. In the HEA-TiC composites, in contrast, the oxidation layers are strengthened by the TiC particles to produce glazed layers, which may efficiently prevent metal-metal contact and reduce friction between the HEA-TiC composites and the counterface. Consequently, the friction and wear properties of the HEA-TiC composites are substantially improved at high temperature [29].

Table 4. Chemical compositions of the surface wear-tested at high temperature, in atomic percentage.

\begin{tabular}{ccccccccc}
\hline $\begin{array}{c}\text { Chemical } \\
\text { Composition }\end{array}$ & Fe & Co & Ni & Cu & Al & Ti & C & O \\
\hline TiC00 & 9.9 & 10.9 & 11.4 & 14.6 & 25.2 & - & - & 28.0 \\
TiC10 & 2.6 & 3.5 & 4.1 & 15.5 & 5.4 & 3.4 & 4.8 & 60.6 \\
TiC20 & 1.5 & 3.7 & 3.4 & 13.0 & 3.9 & 6.8 & 3.0 & 64.7 \\
TiC30 & 1.0 & 2.2 & 3.0 & 15.8 & 3.8 & 9.8 & 4.1 & 60.6 \\
\hline
\end{tabular}

\section{Conclusions}

(1) The FeCoNiCuAl-TiC composites mainly consist of FCC, BCC, and TiC phases. The TiC particles are dispersed in the matrix with a diameter of $0.3 \mu \mathrm{m}$.

(2) The micro-hardness of FeCoNiCuAl-TiC composites increases from 467 to $768 \mathrm{HV}$ with the increase in $\mathrm{TiC}$ content, which is primarily attributed to the strengthening of the hard $\mathrm{TiC}$ phases and the refined microstructures.

(3) The main wear mechanism for the FeCoNiCuAl HEA at room temperature is adhesive wear. The wear mechanisms for the FeCoNiCuAl-TiC composites at room temperature are adhesive wear and abrasive wear. With the increase in TiC, the friction coefficient increases first and then decreases, while the wear loss continually decreases.

(4) The wear mechanism of the FeCoNiCuAl HEA at high temperature is severe adhesive wear. With the addition of $\mathrm{TiC}$, both the friction coefficient and the wear rate reduce considerably. The dominant wear mechanism of HEA-TiC composites at high temperature is oxidative wear. Benefiting from the formation of oxidation layers, the HEA-TiC composite exhibits excellent wear resistance.

Author Contributions: Conceptualization, T.Z. and Y.Y.; methodology, H.W., J.L., and L.L.; data curation, Q.L. and W.H.; writing-original draft preparation, T.Z.; writing—review and editing, T.Z., Y.L., H.W., and R.Z.; supervision, N.Z. and Q.S. All authors have read and agreed to the published version of the manuscript.

Funding: This research was funded by the National Key Research and Development Program (Grant No. 2016YFB1100103), National Natural Science Foundation of China (Grant No. 51771233), Key Research and Development Program of Hunan Province (Grant No. 2016JC2003), China Postdoctoral Science Foundation (Grant No. 2018M633164), Fundamental Research Funds for the Central Universities of Central South University (Grant No. 2018ZZTS127, CX20190190, 2019ZZTS134), and Science and Technology Program of Shenzhen City (JSGG20170824162647398).

Acknowledgments: The authors are grateful to the National Key Research and Development Program.

Conflicts of Interest: The authors declare no conflict of interest.

\section{References}

1. Yeh, J.-W. Nanostructured high-entropy alloys with multiple principal elements. Nov. Alloy Des. Concepts Outcomes 2004, 6, 299-303. [CrossRef] 
2. He, J.Y.; Wang, H.; Huang, H.L.; Xu, X.D.; Chen, M.W.; Wu, Y.; Liu, X.J.; Nieh, T.G.; An, K.; Lu, Z.P. A precipitation-hardened high-entropy alloy with outstanding tensile properties. Acta Mater. 2016, 102, 187-196. [CrossRef]

3. Liu, B.; Wang, J.; Liu, Y.; Fang, Q.; Wu, Y.; Chen, S.; Liu, C.T. Microstructure and mechanical properties of equimolar FeCoCrNi high entropy alloy prepared via powder extrusion. Intermetallics 2016, 75, 25-30. [CrossRef]

4. Poletti, M.G.; Fiore, G.; Gili, F.; Mangherini, D.; Battezzati, L. Development of a new high entropy alloy for wear resistance: FeCoCrNiW 0.3 and FeCoCrNiW $0.3+5$ at.\% of C. Mater. Des. 2017, 115, 247-254. [CrossRef]

5. Butler, T.M.; Weaver, M.L. Oxidation behavior of arc melted AlCoCrFeNi multi-component high-entropy alloys. J. Alloys Compd. 2016, 674, 229-244. [CrossRef]

6. Li, D.; Li, C.; Feng, T.; Zhang, Y.; Sha, G.; Lewandowski, J.J.; Liaw, P.K.; Zhang, Y. High-entropy Al 0.3 $\mathrm{CoCrFeNi}$ alloy fibers with high tensile strength and ductility at ambient and cryogenic temperatures. Acta Mater. 2017, 123, 285-294. [CrossRef]

7. Li, Q.H.; Yue, T.M.; Guo, Z.N.; Lin, X. Microstructure and corrosion properties of AlCoCrFeNi high entropy alloy coatings deposited on AISI 1045 steel by the electrospark process. Metall. Mater. Trans. A 2012, 44, 1767-1778. [CrossRef]

8. Beyramali Kivy, M.; Asle Zaeem, M.; Lekakh, S. Investigating phase formations in cast AlFeCoNiCu high entropy alloys by combination of computational modeling and experiments. Mater. Des. 2017, 127, 224-232. [CrossRef]

9. Zhuang, Y.X.; Xue, H.D.; Chen, Z.Y.; Hu, Z.Y.; He, J.C. Effect of annealing treatment on microstructures and mechanical properties of FeCoNiCuAl high entropy alloys. Mater. Sci. Eng. A 2013, 572, 30-35. [CrossRef]

10. Verma, A.; Tarate, P.; Abhyankar, A.C.; Mohape, M.R.; Gowtam, D.S.; Deshmukh, V.P.; Shanmugasundaram, T. High temperature wear in CoCrFeNiCux high entropy alloys: The role of Cu. Scr. Mater. 2019, 161, $28-31$. [CrossRef]

11. Mao, C.; Zhou, F.; Hu, Y.; Cai, P.; Jiang, Y.; Bi, Z.; Peng, G. Tribological behavior of cBN-WC-10Co composites for dry reciprocating sliding wear. Ceram. Int. 2019, 45, 6447-6458. [CrossRef]

12. Mao, C.; Lu, J.; Zhao, Z.; Yin, L.; Hu, Y.; Bi, Z. Simulation and experiment of cutting characteristics for single cBN-WC-10Co fiber. Precis. Eng. 2018, 52, 170-182. [CrossRef]

13. Zhou, R.; Chen, G.; Liu, B.; Wang, J.; Han, L.; Liu, Y. Microstructures and wear behaviour of (FeCoCrNi) 1-x (WC) $x$ high entropy alloy composites. Int. J. Refract. Met. Hard Mater. 2018, 75, 56-62. [CrossRef]

14. Rogal, Ł.; Kalita, D.; Tarasek, A.; Bobrowski, P.; Czerwinski, F. Effect of SiC nano-particles on microstructure and mechanical properties of the CoCrFeMnNi high entropy alloy. J. Alloys Compd. 2017, 708, 344-352. [CrossRef]

15. Dobeš, F.; Hadraba, H.; Chlup, Z.; Dlouhý, A.; Vilémová, M.; Matějíček, J. Compressive creep behavior of an oxide-dispersion-strengthened CoCrFeMnNi high-entropy alloy. Mater. Sci. Eng. A 2018, 732, 99-104. [CrossRef]

16. Jiang, Q.; Li, X.; Wang, H. Fabrication of TiC particulate reinforced magnesium matrix composites. Scr. Mater. 2003, 48, 713-717. [CrossRef]

17. Yim, D.; Sathiyamoorthi, P.; Hong, S.-J.; Kim, H.S. Fabrication and mechanical properties of TiC reinforced CoCrFeMnNi high-entropy alloy composite by water atomization and spark plasma sintering. J. Alloys Compd. 2018. [CrossRef]

18. Du, X.; Gao, T.; Liu, G.; Liu, X. In situ synthesizing SiC particles and its strengthening effect on an $\mathrm{Al}-\mathrm{Si}-\mathrm{Cu}-\mathrm{Ni}-\mathrm{Mg}$ piston alloy. J. Alloys Compd. 2017, 695, 1-8. [CrossRef]

19. Shu, D.; Li, Z.; Zhang, K.; Yao, C.; Li, D.; Dai, Z. In situ synthesized high volume fraction WC reinforced Ni-based coating by laser cladding. Mater. Lett. 2017, 195, 178-181. [CrossRef]

20. Zhao, N.; Xu, Y.; Fu, Y. Mechanical properties of one-step in situ synthesized NbC-Fe composite coating. Surf. Coat. Technol. 2017, 309, 1105-1110. [CrossRef]

21. Cheng, J.; Liu, D.; Liang, X.; Chen, Y. Evolution of microstructure and mechanical properties of in situ synthesized TiC-TiB2/CoCrCuFeNi high entropy alloy coatings. Surf. Coat. Technol. 2015, 281, 109-116. [CrossRef] 
22. Guo, N.N.; Wang, L.; Luo, L.S.; Li, X.Z.; Chen, R.R.; Su, Y.Q.; Guo, J.J.; Fu, H.Z. Microstructure and mechanical properties of in-situ MC-carbide particulates-reinforced refractory high-entropy Mo0.5NbHf0.5ZrTi matrix alloy composite. Intermetallics 2016, 69, 74-77. [CrossRef]

23. Moravcik, I.; Cizek, J.; Gavendova, P.; Sheikh, S.; Guo, S.; Dlouhy, I. Effect of heat treatment on microstructure and mechanical properties of spark plasma sintered AlCoCrFeNiTi0.5 high entropy alloy. Mater. Lett. 2016, 174, 53-56. [CrossRef]

24. Löbel, M.; Lindner, T.; Lampke, T. Enhanced wear behaviour of spark plasma sintered AlCoCrFeNiTi high-entropy alloy composites. Materials 2018, 11, 2225. [CrossRef] [PubMed]

25. Sakkaki, M.; Sadegh Moghanlou, F.; Vajdi, M.; Shahedi Asl, M.; Mohammadi, M.; Shokouhimehr, M. Numerical simulation of heat transfer during spark plasma sintering of zirconium diboride. Ceram. Int. 2020, 46, 4998-5007. [CrossRef]

26. Ko, Y.G.; Shin, D.H.; Park, K.-T.; Lee, C.S. An analysis of the strain hardening behavior of ultra-fine grain pure titanium. Scr. Mater. 2006, 54, 1785-1789. [CrossRef]

27. Liu, Y.; Wang, J.; Fang, Q.; Liu, B.; Wu, Y.; Chen, S. Preparation of superfine-grained high entropy alloy by spark plasma sintering gas atomized powder. Intermetallics 2016, 68, 16-22. [CrossRef]

28. Fan, Q.C.; Li, B.S.; Zhang, Y. The microstructure and properties of (FeCrNiCo)AlxCuy high-entropy alloys and their TiC-reinforced composites. Mater. Sci. Eng. A 2014, 598, 244-250. [CrossRef]

29. Sun, X.; Zhu, H.; Li, J.; Huang, J.; Xie, Z. Influence of aluminum content on the microstructure and properties of the in-situ TiC reinforced AlxFeCoNiCu high entropy alloy matrix composites. Mater. Sci. Eng. A 2019, 743, 540-545. [CrossRef]

30. Sun, X.; Zhu, H.; Li, J.; Huang, J.; Xie, Z. High entropy alloy FeCoNiCu matrix composites reinforced with in-situ TiC particles and graphite whiskers. Mater. Chem. Phys. 2018. [CrossRef]

31. Rogal, Ł.; Kalita, D.; Litynska-Dobrzynska, L. CoCrFeMnNi high entropy alloy matrix nanocomposite with addition of $\mathrm{Al}_{2} \mathrm{O}_{3}$. Intermetallics 2017, 86, 104-109. [CrossRef]

32. An, Q.; Wang, J.; Liu, Y.; Liu, B.; Guo, W.; Fang, Q.; Nie, Y. Effects of C and Mo on microstructures and mechanical properties of dual-phase high entropy alloys. Intermetallics 2019, 110. [CrossRef]

33. Zhou, R.; Li, M.; Wu, H.; Liu, B.; Liu, Y. Effect of multi-component carbides on the mechanical behavior of a multi-element alloy. Mater. Sci. Eng. A 2019, 758, 99-102. [CrossRef]

34. Inoue, A.T.A.A. Classification of bulk metallic glasses by atomic size difference, heat of mixing and period of constituent elements and its application to characterization of the main alloying element. Mater. Trans. 2005, 46, 2817-2829. [CrossRef]

35. Peng, Y.B.; Zhang, W.; Mei, X.L.; Wang, H.J.; Zhang, M.Y.; Wang, L.; Li, X.F.; Hu, Y. Microstructures and mechanical properties of $\mathrm{FeCoCrNi-Mo} \mathrm{high} \mathrm{entropy} \mathrm{alloys} \mathrm{prepared} \mathrm{by} \mathrm{spark} \mathrm{plasma} \mathrm{sintering} \mathrm{and} \mathrm{vacuum}$ hot-pressed sintering. Mater. Today Commun. 2020. [CrossRef]

36. Sathiyamoorthi, P.; Basu, J.; Kashyap, S.; Pradeep, K.G.; Kottada, R.S. Thermal stability and grain boundary strengthening in ultrafine-grained CoCrFeNi high entropy alloy composite. Mater. Des. 2017, 134, 426-433. [CrossRef]

37. Murty, B.S.; Ranganathan, S.J.M.R. Novel materials synthesis by mechanical alloying/milling. Int. Mater. Rev. 1998, 43, 101-141. [CrossRef]

38. Suryanarayana, C. Mechanical alloying and milling. Prog. Mater. Sci. 2001, 46, 1-184. [CrossRef]

39. Wen, L.H.; Kou, H.C.; Li, J.S.; Chang, H.; Xue, X.Y.; Zhou, L. Effect of aging temperature on microstructure and properties of AlCoCrCuFeNi high-entropy alloy. Intermetallics 2009, 17, 266-269. [CrossRef]

40. Wu, J.-M.; Lin, S.-J.; Yeh, J.-W.; Chen, S.-K.; Huang, Y.-S.; Chen, H.-C. Adhesive wear behavior of AlxCoCrCuFeNi high-entropy alloys as a function of aluminum content. Wear 2006, 261, 513-519. [CrossRef]

41. Moravcikova-Gouvea, L.; Moravcik, I.; Omasta, M.; Vesely, J.; Cizek, J.; Minarik, P.; Cupera, J.; Zadera, A.; Jan, V.; Dlouhy, I. High-strength Al0.2Co1.5CrFeNi1.5Ti high-entropy alloy produced by powder metallurgy and casting: A comparison of microstructures, mechanical and tribological properties. Mater. Charact. 2020, 159, 752-757. [CrossRef]

42. Yu, Y.; He, F.; Qiao, Z.; Wang, Z.; Liu, W.; Yang, J. Effects of temperature and microstructure on the triblogical properties of CoCrFeNiNbx eutectic high entropy alloys. J. Alloys Compd. 2019, 775, 1376-1385. [CrossRef]

43. Zhuang, Y.X.; Liu, W.J.; Chen, Z.Y.; Xue, H.D.; He, J.C. Effect of elemental interaction on microstructure and mechanical properties of FeCoNiCuAl alloys. Mater. Sci. Eng. A 2012, 556, 395-399. [CrossRef] 
44. Zhuang, Y. Effect of Co element on microstructure and mechanical properties of FeCoXNiCuAl alloys.pdf. Acta Metallurgica Sinica 2012. [CrossRef]

45. Kao, Y.-F.; Chen, T.-J.; Chen, S.-K.; Yeh, J.-W. Microstructure and mechanical property of as-cast, -homogenized, and -deformed AlxCoCrFeNi $(0 \leq x \leq 2)$ high-entropy alloys. J. Alloys Compd. 2009, 488, 57-64. [CrossRef]

46. Du, B.; Wang, X.; Zou, Z. Microstructure and tribological behavior of laser in situ synthesized TiC-reinforced Fe-based composite coatings. Tribol. Lett. 2011, 43, 295-301. [CrossRef]

47. Zhou, Z.; Shan, Q.; Jiang, Y.; Li, Z.; Zhang, Z. Effect of nanoscale V2C precipitates on the three-body abrasive wear behavior of high-Mn austenitic steel. Wear 2019, 436-437. [CrossRef]

48. Archard, J.F. Contact and rubbing of flat surfaces. J. Appl. Phys. 1953, 24, 981-988. [CrossRef]

49. Chuang, M.-H.; Tsai, M.-H.; Wang, W.-R.; Lin, S.-J.; Yeh, J.-W. Microstructure and wear behavior of AlxCo1.5CrFeNi1.5Tiy high-entropy alloys. Acta Mater. 2011, 59, 6308-6317. [CrossRef]

50. Stott, F.H. High-temperature sliding wear of metals. Tribol. Int. 2002, 35, 489-495. [CrossRef]

(C) 2020 by the authors. Licensee MDPI, Basel, Switzerland. This article is an open access article distributed under the terms and conditions of the Creative Commons Attribution (CC BY) license (http://creativecommons.org/licenses/by/4.0/). 